\title{
Extrato da casca de Syzygium cumini no controle da glicemia e estresse oxidativo de ra- tos normais e diabéticos ${ }^{1}$
}

\author{
Syzygium cumini bark extract in controling glycemia and oxidative stress of normal and diabetic rats
}

\author{
Cinthia Melazzo Mazzanti ${ }^{2}$ Deila Rosély Schossler ${ }^{3}$ Andreane Filappi $^{4}$ Danívia Prestes $^{4}$ \\ Daniela Balz ${ }^{5}$ Vinícius Miron ${ }^{5}$ André Morsch ${ }^{5}$ Maria Rosa Chitolina Schetinger $^{6}$ \\ Vera Maria Morsch ${ }^{6}$ Marcelo Cecim $^{7}$
}

\section{RESUMO}

\begin{abstract}
O Syzygium cumini, também conhecido como Jambolão é amplamente utilizado na medicina popular para o tratamento da diabetes melito. Este estudo verificou a eficiência do extrato da casca de Syzygium cumini sobre os niveis glicêmicos e estresse oxidativo de ratos normais e diabéticos induzidos por aloxano. Os animais foram divididos em grupo controle $(C)$, controle tratado $(C T)$, diabético controle $(D C)$ e diabético tratado (DT). A administração oral do extrato aquoso da casca de Jambolão, na dose de $1 \mathrm{~g} / \mathrm{kg}$ de peso vivo, por um periodo de trinta dias, não resultou em uma redução significativa na glicemia e nos niveis de hemoglobina glicosilada. Neste estudo, o tratamento com o extrato demonstrou um aumento dos niveis de substâncias reativas ao ácido tiobarbitúrico (TBA-RS) no plasma dos ratos do grupo $D T(P<0,05)$, comparado com o $C$. A atividade da catalase nos rins dos ratos do grupo DC diminuiu significativamente $(P<0,01)$ e no fígado houve uma elevação significativa dessa enzima no grupo $D C(P<0,01)$. Estes resultados indicam que o extrato da casca do Jambolão não possui efeito hipoglicemiante em ratos diabéticos induzidos pelo aloxano. O efeito antioxidante desta planta não foi suficiente para diminuir significativamente a produção de TBA-RS. A diminuição da atividade da catalase nos
\end{abstract}

rins pode ser devida à exaustão ou inibição desta enzima e seu aumento, no fígado, devido ao estresse oxidativo, ocasionado pelo estado diabético.

Palavras-chave: Jambolão, Syzygium cumini, aloxano, diabetes, estresse oxidativo.

\section{ABSTRACT}

The plant Syzygium cumini, also known as Black Plum is used widely in the popular medicine for the treatment of diabetes mellitus. This study verified the efficiency of the extract of the bark of Syzygium cumini on the glycemic levels and oxidative stress of normal and diabetic rats induced by alloxan. The animals were divided in control group $(C)$, control treatment group (CT), diabetic control group (DC) and diabetic treatment group (DT). Oral administration of the aqueous extract of the bark of Syzygium cumini, in the dose of $1 \mathrm{~g} / \mathrm{kg}$ live weight, for a period of thirty days, did not result in a significant reduction on glycemia or on glucosilated hemoglobin levels. The treatment with the extract demonstrated an increase in the levels of thiobarbituric acid reactive substances $(T B A-R S)$ in the plasma of the DT group $(P<0.05)$, compared to the $C$. Kidney catalase activity of rats in $D C$ group decreased significantly $(P<0.01)$ and, in the liver, it showed a significant elevation in group DC $(P<0.01)$. Those

${ }^{1}$ Parte da dissertação de Mestrado do primeiro autor ao programa de Pós-graduação em Medicina Veterinária (PPGMV), Universidade Federal de Santa Maria (UFSM). Trabalho realizado com suporte financeiro da Fundação de Amparo à Pesquisa do Estado do Rio Grande do Sul.

${ }^{2}$ Médico Veterinário, aluno do PPGMV, UFSM.

${ }^{3}$ Professora do Departamento de Morfologia da UFSM.

${ }^{4}$ Médico Veterinário, aluno do PPGMV, UFSM.

${ }^{5}$ Aluno do Programa de Pós-graduação em Bioquímica Toxicológica da UFSM.

${ }^{6}$ Professora Adjunta do Departamento de Bioquímica da UFSM.

${ }^{7}$ Médico Veterinário, PhD, Professor Adjunto do Departamento de Clínica de Grandes Animais da UFSM. Camobi. 97105-900, Santa Maria, RS. Email:mcecim@lince.hcv.ufsm.br. Autor para correspondência. 
results indicated that the extract of Syzygium cumini bark does not possess hypoglycemic effect in alloxan diabetic induced rats. The antioxidant effect of this plant was not enough to reduce the production of TBA-RS significantly. The decrease of catalase activity in the kidneys can be owed to its exhaustion or inhibition, and its increase in the liver could be due to oxidative stress caused by the diabetic status.

Key words: Black Plum, Syzygium cumini, alloxan, diabetes, oxidative stress

\section{INTRODUÇÃO}

A diabetes melito compreende um grupo heterogêneo de transtornos hiperglicêmicos, que afetam o metabolismo de carboidratos, lipídeos e proteínas e estão associados com uma deficiência absoluta ou relativa na secreção e/ou ação da insulina (RAO et al., 2001).

A Ayuverdica, um sistema tradicional de medicina da Índia, utiliza há séculos, plantas com propriedades medicinais, para o tratamento de diversas doenças, inclusive da diabetes melito, sendo o Syzygium cumini uma das plantas mais utilizadas para o controle desta endocrinopatia (PRINCE et al., 1998).

Syzygium cumini (sinonímias: Syzygium jambolanum, Eugenia jambolana, Syzygium jambos) é uma arvore originária da Índia, pertencente à família das Mirtáceas e vulgarmente conhecida no Brasil como Jambolão, podendo ser encontrada em diversos estados do Brasil, incluindo $\mathrm{MG}, \mathrm{RJ}$, RS e SP (BRAGANÇA, 1996). A casca, o fruto, a semente e a folha dessa planta, são freqüentemente utilizados no tratamento da diabetes melito e administrados na forma de diferentes preparados como extrato aquoso ou decocção, extrato etanólico ou o suco da planta crua (PEPATO et al., 2001).

A diabetes melito insulino dependente (DMID) é caracterizada por uma série de complicações que afetam distintos órgãos e os radicais livres de oxigênio podem estar envolvidos na patogênese dessa endocrinopatia (KAKKAR et al., 1995). Durante a hiperglicemia persistente da diabetes, ocorre um aumento da produção de radicais livres de oxigênio através da auto-oxidação da glicose, e esses radicais exercem seus efeitos citotóxicos nos fosfolipídeos de membrana, resultando na formação de malondialdeído (MDA), um produto final da peroxidação lipídica, o qual reage com o ácido tiobarbitúrico (AYOUB et al., 2000).

Para a criação de um modelo experimental da diabetes melito, têm-se empregado várias substâncias, podendo-se citar entre elas, o aloxano. Sua ação diabetogênica caracteriza-se pela produção de radicais livres que são tóxicos, especificamente nas células $\beta$ do pâncreas, levando à degeneração e morte definitiva das mesmas (GRANKVIST et al., 1979). Essa citotoxidade seletiva do aloxano é devido à grande capacidade da célula $\beta$ em acumular a droga, aliada ao fato de esta célula demonstrar uma maior sensibilidade aos radicais peróxidos, quando comparada a outros tecidos (JORNS et al., 1999).

A diabetogenicidade do aloxano pode ser prevenida por diversas substâncias, que diminuem a suscetibilidade das células alvo ao agente agressor. Entre elas, podem-se citar a superóxido dismutase (SOD) e a catalase (CAT), enzimas que agem, profilaticamente, contra a toxicidade do aloxano sobre as células $\beta$, in vivo e in vitro (JORNS et al., 1999).

O presente trabalho teve como objetivo verificar a eficiência do extrato da casca de Syzygium cumini sobre os níveis glicêmicos e o estresse oxidativo de ratos normais e diabéticos induzidos pelo aloxano.

\section{MATERIAL E MÉTODOS}

O estudo foi realizado em 39 ratas adultas da linhagem Wistar, pesando entre 180 e $300 \mathrm{~g}$, provenientes do Biotério Central da Universidade Federal de Santa Maria (UFSM). A dieta sólida ${ }^{a}$, bem como a hídrica, foram fornecidas ad libitum. Antes do início do experimento, os animais passaram por um período de adaptação de dez dias.

O material vegetal (casca do caule) de Syzygium cumini, foi seco, inicialmente sob luz, evitando-se a presença de fungos e, após em estufa, a temperatura de $50^{\circ} \mathrm{C}$, sendo em seguida processado em moinho Wiley. De posse do material moído, passouse a fazer a extração a frio, utilizando-se etanol como solvente, e depois de várias extrações e com a evaporação do solvente em rotavapor com pressão reduzida, obteve-se um resíduo escuro viscoso, denominado extrato bruto com rendimento de $10 \%$ do peso original da casca do caule.

Para a indução da DMID, administrou-se aloxano $^{\text {b }}$ (diluído a $2 \%$ em solução de citrato de sódio $0,05 \mathrm{M}, \mathrm{pH} 4,5)$ na dose de $150 \mathrm{mg} \cdot \mathrm{kg}^{-1}$, via intraperitoneal, dose única, após um período de jejum de 24 horas. Após 6 horas da indução, foi fornecida uma solução de glicose $10 \%$ como única fonte hídrica, durante 24 horas, para evitar uma hipoglicemia fatal, devido à liberação maciça de insulina que ocorre após a destruição das células $ß$. Após 15 dias, a glicose sanguínea foi determinada e os animais que apresentaram uma glicemia inferior a $180 \mathrm{mg}^{\mathrm{dL}} \mathrm{dL}^{-1}$ foram novamente induzidos, seguindo o mesmo protocolo. 
Somente os animais com glicemia de jejum superior a $180 \mathrm{mg} . \mathrm{dl}^{-1}$ foram considerados diabéticos e selecionados para o experimento.

Os animais foram alocados, de forma aleatória em 4 grupos: Grupo1: controle $(\mathrm{C}=11)$; Grupo 2: controle tratado $(\mathrm{CT}=9)$; Grupo 3: diabético controle $(\mathrm{DC}=10)$; Grupo 4: diabético tratado $(\mathrm{DT}=9)$. Esses grupos representam situações de normalidade, prevenção, enfermidade e tratamento. Os grupos 1 (C) e 3 (DC) receberam diariamente $2 \mathrm{ml}$ de água destilada através de uma sonda oroesofágica (gavagem), e os grupos $2(\mathrm{CT})$ e 4 (DT) receberam diariamente pela mesma via o extrato da casca de Syzygium cumini na dose de $1 \mathrm{~g} . \mathrm{kg}^{-1}$ de peso vivo.

O tratamento foi realizado por um período de 30 dias e após, as amostras sangüíneas foram coletadas por punção cardíaca, com os animais em jejum sólido de 16 horas e sob anestesia inalatória em campânula com éter. $O$ sangue foi coletado com auxílio de uma seringa de $10 \mathrm{ml}(25 \times 8)$, contendo EDTA para posterior análise de hemoglobina glicosilada. O plasma foi separado e refrigerado para avaliação de substâncias reativas ao ácido tiobarbitúrico (TBA-RS), as quais refletem a quantidade de radicais livres. Os órgãos (fígado e rins) foram coletados e acondicionados à temperatura de $-4^{\circ} \mathrm{C}$ para posterior estimativa da atividade enzimática da catalase (CAT). Os níveis plasmáticos de glicose foram determinados, a partir de amostras sangüíneas coletadas da veia caudal, através do uso de um glucômetro ADVANTAGE (Boehringer Mannheim, USA) e a dosagem de hemoglobina glicosilada foi realizada através de kits comerciais $\left(\right.$ LABTEST) ${ }^{\mathrm{C}}$. As substâncias reativas ao ácido tiobarbitúrico (TBA-RS) foram determinadas pelo método proposto por JENTZSCH et al. (1996) e a atividade da catalase pelo método de NELSON \& KIESOW (1972).

Realizou-se análise estatística dos valores obtidos de glicose sangüínea, hemoglobina glicosilada, TBA-RS no plasma e catalase nos rins e no fígado. Todos os resultados foram indicados pela média \pm EPM. Realizou-se uma análise de variância (ANOVA) de uma via, com o teste de comparações múltiplas de Tukey-Kramer.

\section{RESULTADOS E DISCUSSÃO}

Os níveis de glicose sangüínea e de hemoglobina glicosilada nos animais deste estudo, demonstraram uma elevação significativa nos grupos DC e DT $(\mathrm{P}<0,001)$, comparado com o grupo C (Tabela 1). A administração do extrato aquoso da casca de Syzygium cumini na dose de $1 \mathrm{~g} . \mathrm{kg}^{-1}$, durante o período de tratamento não demonstrou efeito hipoglicemiante, que foi comprovado pelos valores da hemoglobina glicosilada no final do tratamento, onde também se confirmou o estado diabético induzido pelo aloxano. A falta de efeito hipoglicemiante da casca de Syzygium cumini, observado neste estudo, não exclui a possibilidade de obter uma atividade antidiabética com a planta, coletada em outras regiões do país e em outra época do ano. Também existe a possibilidade dos princípios ativos estarem mais concentrados em outras partes da planta (BRAGANÇA, 1996; PEPATO et al., 2001).

Num estudo realizado em ratos por GROVER et al. (2000), o tratamento com o extrato do caroço de Eugenia jambolana, demonstrou efeito anti-hiperglicemiante em uma glicemia média maior que $175 \mathrm{mg} . \mathrm{dL}^{-1}$ e moderada, maior que $250 \mathrm{mg} . \mathrm{dL}^{-1}$. Esses autores ainda citaram que a diminuição na glicose plasmática é dependente dos protocolos de indução de diabetes que variam na intensidade da hiperglicemia. Isso implicaria que o efeito antihiperglicêmico desta planta seja dependente da dose do agente diabetogênico e no grau de destruição da célula $\beta$ (RAO et al., 2001). Além disso, AYOUB et al. (2000) citaram que esse fato seria um indicativo indireto

Tabela 1 - Níveis de glicose sangüínea (mg/dL) e hemoglobina glicosilada (\%) em ratos normais e diabéticos tratados com o extrato da casca de Syzygium cumini por um período de trinta dias.

\begin{tabular}{lccc}
\hline & \multicolumn{2}{c}{ Glicemia de jejum } & Hemoglobina glicosilada \\
\cline { 2 - 3 } & Antes tratamento & Após tratamento & Após tratamento \\
\hline Controle $(\mathrm{C}=11)$ & $93,9 \pm 3,30(\mathrm{~b})$ & $91,5 \pm 6,20$ & $5,54 \pm 0,17(\mathrm{e})$ \\
Controle tratado $(\mathrm{CT}=9)$ & $102,3 \pm 3,69$ (b) & $110,5 \pm 4,97$ & $5,58 \pm 0,10(\mathrm{e})$ \\
Diabético controle $(\mathrm{DC}=10)$ & $401,7 \pm 47,67$ (a) & $299,0 \pm 28,66$ & $13,43 \pm 1,24(\mathrm{~d})$ \\
Diabético tratado $(\mathrm{DT}=9)$ & $354,4 \pm 39,3$ (a) & $241,0 \pm 36,48$ & $12,2 \pm 1,80(\mathrm{~d})$ \\
\hline
\end{tabular}

Os valores expressos representam as médias \pm erro padrão da média (EPM); médias na mesma coluna seguidas de letras diferentes diferem significativamente $(\mathrm{P}<0,001)$ entre si.

Ciência Rural, v. 33, n. 6, nov-dez, 2003. 
de que parte da atividade hipoglicemiante do Syzygium cumini, seja através da liberação de insulina pela células $\beta$ pancreáticas. Assim, a diabetes induzida nos animais deste experimento, considerada severa (glicose plasmática maior que $400 \mathrm{mg}$. $\mathrm{dL}^{-1}$ ) e o período de tratamento de trinta dias, provavelmente contribuíram para ineficácia do extrato da casca de jambolão em diminuir a glicemia.

A administração do extrato da casca de Syzygium cumini aumentou significativamente o nível de TBA-RS no plasma do grupo DT $(\mathrm{P}<0,05)$, comparado com o grupo $\mathrm{C}$ (Tabela 2). Os danos teciduais mediados por peróxidos de lipídeos têm sido observados no desenvolvimento da diabetes dos tipos I e II (PRINCE et al., 1998). A DMID foi induzida com aloxano, sendo esse fármaco reduzido por agentes biológicos como a cisteína, glutationa e ascorbato até ácido dialúrico, estabelecendo um ciclo redox pela geração de superóxido e peróxido de hidrogênio (GRANKVIST et al., 1979). Além disso, JORNS et al. (1999) citaram que a hiperglicemia induzida pelo aloxano aumenta os radicais livres de oxigênio através da auto-oxidação da glicose e glicosilação protéica não-enzimática. O aumento do TBA-RS, no plasma de ratos diabéticos tratados, pode ser atribuído ao aumento na produção desses radicais livres em excesso da capacidade dos mecanismos de defesa celular (KAKKAR et al., 1995; WHAIEB, 2001). Esta ação não demonstrou efeito antiperoxidativo do extrato da casca do jambolão, e sim pode ter potencializado o estresse oxidativo produzido pelo estado diabético.

As concentrações de peróxidos de lipídeos no fígado e rins, também observadas no estado diabético por PRINCE et al. (1998), demonstraram que o extrato da semente de Syzygium cumini têm propriedades antioxidantes, protegendo esses tecidos. Os autores concordam que a peroxidação lipídica é uma conseqüência da deteriorização oxidativa de

Tabela 2 - Concentração de substâncias reativas ao ácido tiobarbitúrico (TBA-RS) no plasma de ratos normais e diabéticos tratados com o extrato da casca de Syzygium cumini por um período de trinta dias.

\begin{tabular}{lc}
\hline GRUPO & TBA-RS (nmol/mL de plasma) \\
\hline Controle $(\mathrm{C}=11)$ & $99,8 \pm 6,51(\mathrm{~b})$ \\
Controle tratado $(\mathrm{CT}=9)$ & $100,2 \pm 8,82(\mathrm{~b})$ \\
Diabético controle $(\mathrm{DC}=10)$ & $118,0 \pm 10,6(\mathrm{a})$ \\
Diabético Tratado $(\mathrm{DT}=9)$ & $134,2 \pm 9,43$ (a) \\
\hline
\end{tabular}

Os valores expressos representam as médias \pm erro padrão da média (EPM); médias seguidas de letras diferentes diferem significativamente $(\mathrm{P}<0,05)$ entre si. lipídeos poliinsaturados da membrana e que, segundo WOHAIEB (1993), o fígado, os rins e o pâncreas demonstraram ser os principais orgãos-alvo ao estresse oxidativo.

Foi observado, neste estudo, uma diminuição significativa na atividade da catalase nos rins dos ratos do grupo $\mathrm{DC}(\mathrm{p}<0,01)$, comparado com o DT (Tabela 3). Essa diminuição pode ser devido à exaustão e/ou inibição na atividade da catalase (KAKKAR et al.,1995) ou ao resultado de efeitos deletérios causados pelo acúmulo de radicais superóxidos e peróxido de hidrogênio (PRINCE et al., 1998). No fígado, foi observada uma elevação significativa da catalase no grupo DC $(p<0,05)$ comparado com o grupo C (Tabela 3). Este aumento, segundo KAKKAR et al. (1995) na atividade enzimática é devido ao estresse oxidativo, ocasionado pelo estado diabético e por alta produção de peróxido de hidrogênio. Os autores ainda citaram que a hipoinsulinemia, característica da diabetes tipo I, aumenta a atividade da enzima acil-CoA oxidase, que inicia a beta oxidação dos ácidos graxos, resultando na produção de peróxido de hidrogênio. Além disso, JORNS et al. (1999) relataram que o peróxido de hidrogênio não é somente tóxico para as células, mas é também permeável à membrana celular, podendo no meio extracelular reagir com metais de transição, como ferro e cobre, gerando radicais hidroxila altamente reativos, que podem causar dano celular. Essas considerações poderiam justificar o aumento na atividade da catalase no fígado dos ratos diabéticos deste estudo, já que a diabetes induzida pelo aloxano foi do tipo I.

A administração do extrato da casca de Syzygium cumini resultou no aumento significativo na atividade da catalase nos rins e fígado dos ratos do

Tabela 3 - Atividade da catalase (CAT) nos tecidos renal e hepático de ratos normais e diabéticos tratados com o extrato da casca de Syzygium cumini por um período de trinta dias.

\begin{tabular}{lcc}
\hline \multirow{2}{*}{ Grupo } & \multicolumn{2}{c}{ CAT $($ ÄE/proteína/min) } \\
\cline { 2 - 3 } & Rim & Fígado \\
\hline Controle $(\mathrm{C}=4)$ & $0,320 \pm 0,10(\mathrm{~b})$ & $0,271 \pm 0,01(\mathrm{e})$ \\
Controle Tratado $(\mathrm{CT}=4)$ & $0,124 \pm 0,01(\mathrm{~b})$ & $0,665 \pm 0,06(\mathrm{~d})$ \\
Diabético controle $(\mathrm{DC}=4)$ & $0,175 \pm 0,006(\mathrm{~b})$ & $0,491 \pm 0,07(\mathrm{f})$ \\
Diabético Tratado $(\mathrm{DT}=4)$ & $0,515 \pm 0,04(\mathrm{a})$ & $0,740 \pm 0,01(\mathrm{~g})$ \\
\hline
\end{tabular}

Os valores expressos representam as médias \pm erro padrão da média (EPM); médias na mesma coluna seguidas de letras diferentes diferem significativamente $(\mathrm{P}<0,05)$ entre si.

$\Delta \mathrm{E}=$ Expressa o decaimento da absorbância no período de um minuto, relativo ao consumo de peróxido de hidrogênio no meio de reação. 
grupo DT $(\mathrm{P}<0,05)$, comparado com o DC (Tabela 3$)$. Foi também observado um aumento significativo na atividade da catalase no fígado do grupo $\mathrm{CT}(\mathrm{p}<0,001)$, comparado com o C (Tabela 3 ). Esses resultados demonstram que a casca do extrato do jambolão possui atividade removedora de radicais livres, na qual exercem uma ação benéfica, contra alterações patológicas, causadas pela presença de radicais superóxidos e hidroxil, mas que não foi suficiente para amenizar o estresse oxidativo provocado pelo estado diabético.

\section{CONCLUSÕES}

Com base nos resultados obtidos neste estudo, pode-se concluir que o extrato da casca de Syzygium cumini não possui efeito sobre a hiperglicemia e não é eficiente no controle do estresse oxidativo ocasionado pelo estado diabético em ratos.

\section{FONTES DE AQUISIÇÃO}

a- SUPRA LAB, Alisul Ind. Alimentos Ltda, São Leopoldo, RS. b- ALLOXAN MONOHYDRATE, Sigma-Aldrich Inc, St Louis, MO, USA.

c- LABTEST DIAGNÓSTICA, Lagoa Santa, MG.

\section{REFERÊNCIAS BIBLIOGRÁFICAS}

AYOUB, R.S.; YOUSIF, W.H.; AZIZ, B.N. Serum glucose, cholesterol and total lipids levels and tissue lipid peroxidation in alloxan-diabetic rats treated with aqueous extract of Nigella sativa seeds. Iraqi Journal of Veterinary Sciences, v.13, n.1, p.4349, 2000.

BRAGANCA, L.A.R. Aspectos gerais no preparo e no controle de qualidade de plantas e fitoterápicos hipoglicemiantes. In: SIXEL, P.J. Plantas medicinas antidiabéticas: uma abordagem multidisciplinar. Rio Janeiro : Universidade Federal Fluminense, 1996. Cap.5, p.105-122.

GRANKVIST, K. et al. Superoxide dismutase, catalase and scavengers of hydroxyl radical protect against the toxic action of alloxan on pancreatic islet cells in vitro. Biochemical Journal, v.182, p.17-25, 1979.

GROVER, J.K.; VATS, V.; RATHI, S.S. Antihyperglicemic effect of Eugenia jambolana and Tnospora cordifolia in experimental diabetes and their key metabolic enzymes involved in carbohydrate metabolism. Journal of Ethnopharmacology, v.73, p.461-470, 2000 .

JENTZSCH, A.M. et al. Improved analysis of malondialdehyde in human body fluids. Free Radical \& Medicine, v.20, n.2, p.251256, 1996.

JORNS, A. et al. Effect of superoxide dismutase, catalase, chelating agents, and free radical scavengers on the toxicity of alloxan to isolated pancreatic islets in vitro. Free Radical Biology \& Medicine, v.26, n.10, p.1300-1304, 1999.

KAKKAR, R. et al. Lipid peroxidation and activity of antioxidant anzymes in diabetic rats. Molecular and Celular Biochemistry, v.151, p.113-119, 1995.

NELSON, D.P.; KIESOW, L.A. Entalpy of the composition of hidrogen peroxide by catalase at $25^{\circ} \mathrm{C}$. Analytical Biochemistry, v.49, p.474-479, 1972.

PEPATO, M.T. et al. Lack of antidiabetic effect of a Eugenia Jambolana leaf decoction on rat streptozotocin diabetes. Brazilian Journal of Medical and Biological Research, v.34, p.389-395, 2001.

PRINCE, P.S.M.; MENON, V.P.; PARI, L. Hypoglycaemic ativity of Syzygium cumini seeds: effect on lipid peroxidation in alloxan diabetic rats. Journal of Ethnopharmacology, v.61, p.1-7, 1998.

RAO, B.K.; KESAVULU, M.M.; APPARAO, C.H. Antihyperglicemic activity of Momordica cymbalaria in alloxan diabetic rats. Journal of Ethnopharmacology, v.78, p.67-71, 2001.

WHAIEB, S.A. $\mathrm{H}_{2} \mathrm{O}_{2}$ exposure during pregnancy: the effect of vitamin $\mathrm{C}$ against oxidative stress in the offspringof rats. Iraqi Journal of Veterinary Sciences, v.14, n.1, p.17-28, 2001.

WOHAIEB, S.A. Effect of insulin treatment on tissue lipid peroxidation in chronic alloxan diabetes in the rabbit. Iraqi Journal of Veterinary Sciences, v.6, n.2, p.98-101, 1993. 